\title{
Tax Interaction Dynamics among Belgian Municipalities
}

J.F. Richard, H. Tulkens and M. Verdonck

Discussion Paper 2005-39

\section{Département des Sciences Économiques de l'Université catholique de Louvain}


Département des Sciences Économiques de l'Université catholique de Louvain

Institut de Recherches Économiques et Sociales

Place Montesquieu, 3

1348 Louvain-la-Neuve, Belgique 


\title{
Tax Interaction Dynamics among Belgian Municipalities 1984-1997*
}

\author{
Jean François Richard, University of Pittsburgh \\ Henry Tulkens and Magali Verdonck, CORE, Université catholique de Louvain
}

CORE Discussion Paper n²005/48

June 2005

\begin{abstract}
The purpose of this paper is to test econometrically the existence of fiscal interactions between Belgian municipalities. At the time of writing, the motivation was to provide scientific support to the lively debate on fiscal competition that took place among Belgian politicians in the late nineties.

Two types of taxes are considered, for which Belgian municipalities have the decision power as to rates: the "centimes additionnels" on the personal income tax and the "précompte immobilier" which is a property tax. A dynamic adjustment model is specified and estimated using panel data for 598 municipalities over 15 years.

The empirical results obtained bear upon two main points: (i) Some interaction definitely has prevailed between the municipalities' fiscal choices made during the observation period, for both taxes; (ii) However, the adjustment reactions to the other municipalities' fiscal choices have occurred over time at the very low yearly pace of $6 \%$ and $10 \%$, respectively, of the discrepancy between the actual rates and the preferred rates.
\end{abstract}

\footnotetext{
Center for Operations Research and Econometrics

34 voie du Roman Pays

B-1348 Louvain-la-Neuve

Belgium

Tel.: +32(0)10474332

Email: tulkens@core.ucl.ac.be
}

\footnotetext{
* Translated from a French version that appeared in Économie et Prévision (Ministry of Finance, Paris), $\mathrm{n}^{\circ} 156$, 2002/5, 1-14.
} 


\title{
Tax Interaction Dynamics among Belgian Municipalities 1984-1997
}

\author{
Jean François Richard, University of Pittsburgh \\ Henry Tulkens and Magali Verdonck, CORE, Université catholique de Louvain
}

\section{Introduction and review of the literature}

Tax interaction occurs when the taxation decisions taken by one independent authority are influenced by the taxation decisions of neighbouring authorities. We see two possible sources of this type of interaction. The first is tax competition. In this case the transmission channel for tax interaction is the geographic mobility of tax bases: by using tax instruments, governments attempt to acquire a mobile tax base. Their interest in doing this is to increase their income (or not to decrease it), and to benefit from the advantages linked to the presence of these tax bases (more investment, more jobs, etc). The second source of tax interaction is tax mimicry for political reasons. In this case, it is not the mobility of tax bases that forms the transmission channel, but the fear of the political decision-makers of being penalised by their electorate if their tax decisions are seen as being worse than their neighbours. These two sources of tax interaction are analysed from a theoretical point of view, according to two distinct streams of thought in the literature: tax competition and tax mimicry, sometimes called "yardstick competition".

The objective of this article is to empirically test the existence of tax interactions in Belgium, at the local government level, i.e. the municipalities ${ }^{1}$. It is thus not about determining the channel through which these interactions are transmitted ${ }^{2}$.

There is nascent empirical literature aimed at testing the presence of tax interactions. We have listed eight articles that attempt to answer the following question: "Do political decision-makers take account of the decisions of their neighbours when making their tax choices, and if yes, to what extent?" All these articles, except one, are based on North American data. The majority examine the choices in terms of tax rates, and one of them examines the choices in terms of expenditure (Case, Rosen and Hines, 1993). Different types of taxes are considered: personal income tax (Heyndels and Vuchelen 1996, Goodspeed 1999, and Case 1993), corporate income tax (Masayoshi and Boadway, 2000), wealth tax (Brueckner and Saavedra 1999), excises (Besley and Rosen, 1998) and the tax burden as a whole (Ladd, 1992).

The empirical studies always include a reminder of the theoretical foundations of the phenomenon studied. They cover the two aforementioned streams: tax competition ${ }^{3}$, and yardstick competition. When the authors consider taxes on mobile bases (wealth tax or

\footnotetext{
1 This exercise was done in order to shed scientific and empirical light on the debate concerning tax competition that took place in Belgium during the institutional negotiations of October 2000. The issue of increased fiscal autonomy of the Regions was a central one. A detailed account of these negotiations and their results is given in Van der Stichele and Verdonck (2001).

2 The reader interested in empirical studies bearing specifically on the mobility of tax bases should read the articles of Feld and Kirschgässner (2000), Goodspeed (1999) as well as Heyndels and Vuchelen (1989).

${ }^{3}$ For a recent review of the theoretical literature on tax competition see Wilson (1999).
} 
indirect taxes), their empirical study is generally preceded by a theoretical model of tax competition. When they look at taxes on less mobile bases (tax on income from labour), their empirical study is sometimes preceded by a theoretical model of the yardstick competition type.

Irrespective of the basic theoretical model adopted to study the existence of tax interaction, the specification of the econometric model to perform the test it is the same. In fact, the variable to be explained is the rate chosen by the entities considered, and the equation to be estimated is a linear equation containing the socio-economic variables of the entity concerned, as well as the rates of the neighbouring entities. The major variant among the estimated equations concerns the method for weighting the rates of neighbouring entities, in order to account for the fact that an entity can be more strongly influenced by certain entities and less so by others.

In these articles, the presence of tax interaction is accepted if significant coefficients are obtained for the explanatory variables, which are the rates of neighbouring entities. The studies conclude by noticing the existence of significant interaction between entities at the same level of government, with this interaction being positive in the vast majority of cases. The results indicate that the estimated coefficient for the rates of neighbouring municipalities is of the order of 0.6 on average. Several authors end their studies with the following interpretation: "If all neighbours of entity $i$ increase their tax rates by $1 \%$, entity $i$ will increase its tax rate by $0.6 \%$ ".

For the following reasons, we believe that this interpretation is incorrect. The previously mentioned studies analyse the problem statically, i.e. one year at a time. The data themselves often only relate to a single year, and if several years are considered, the analysis is done for each year separately. This means that the econometric results obtained implicitly assume that each municipality is able to effectively adopt its preferred rate of tax in the year of observation, given the rates of its neighbours. To us, this hypothesis seems to be too strong, and above all untenable if, as we have been able to do here, the analysis is done over a large number of consecutive years. In this context we cannot ignore varying adjustment times in the decision-making process. This thus has to be taken into account when evaluating the actual tax interaction phenomenon.

That is why we specify a dynamic model that explicitly takes adjustment time into account. The observed changes in the tax rates will then be interpreted as trends towards a rate that we call the municipality's "preferred rate" - rate that is subject to external influences such as the rates of the other municipalities, or even other economic variables that play a role in fiscal decisions. Thus, each rate change observed will not be interpreted as resulting from tax interactions, but as a movement towards the preferred rate. It is in the level of this rate that the presence of tax interactions is explicitly acknowledged as a possibility. That this presence can be detected in the facts is precisely what this econometric estimate aims to verify.

The analysis is organised as follows. A model of the assumed tax behaviour of each municipality is specified in section 2 . The data used for the empirical analysis are described in section 3. The econometric method used is contained in section 4 . The results of the estimates and their econometric interpretation are presented in section 5. Section 6 presents a summary and draws conclusions from the study.

\section{Specification of the economic model}

The model assumed to describe the behaviour of municipalities in the choice of their tax rates is set out in two stages. We start by defining the tax rate that we call the "preferred rate" of a local entity, and then describe an adjustment process over time towards this preferred rate. 
We present a model in terms of a single tax. When more than one type of tax is used, the model is assumed to apply to each tax separately.

\subsection{The preferred rate in the absence of tax interaction}

First suppose that for each municipality $i$ there is a tax rate $T_{i, t}^{*}$ that it would apply in year $t$ if it did not have to take any account of the other municipalities. It would choose this rate according to the economic conditions that we will represent by a vector $Z_{i, t}$ of miscellaneous variables, and also by considering the tax rate set by a different level of authority on the same basis $T_{F, t}$. This last element takes account of any vertical tax interaction between the municipalities and the other levels of government (regional or federal for Belgium). We summarise these conditions by specifying the equation

(1) $T_{i}^{*}=\beta^{\prime} Z_{i}+\alpha T_{F}$

where the time index has been omitted because it is not essential at this stage, $\alpha$ is a scalar and $\beta$ a vector of the same dimension as $Z_{i}$. We will call $T_{i}^{*}$ the "preferred rate of the municipality $i$ in the absence of tax interaction".

However, during the period studied, the relevant tax rates of the other levels of government did not change or only changed once, which does not allow their impact to be measured. We will thus ignore them and replace (1) by

(2) $T_{i}^{*}=\beta^{\prime} Z_{i}$

\subsection{The preferred rate in the presence of tax interaction}

In order to take account of any tax interactions between municipalities, we amend the concept of preferred rate that has just been presented, by alternatively taking "the preferred tax rate of municipality $i$, in year $t$, in the presence of tax interactions", denoting it as $\widetilde{T}_{i, t}$ and writing the equation that determines it in the form (again without the index $t$ )

$$
\text { (3) } \begin{aligned}
\widetilde{T}_{i} & =\phi_{i i} T_{i}^{*}+\sum_{\substack{j=1 \\
j \neq i}}^{n} \phi_{i j} T_{j} \\
& =\phi_{i i}\left(T_{i}^{*}-T_{i}\right)+\sum_{j=1}^{n} \phi_{i j} T_{j}
\end{aligned}
$$

with

(4) $\sum_{j=1}^{n} \phi_{i j}=1$

\footnotetext{
${ }^{4}$ It is not an optimum rate as we do not derive it from a model of optimisation. Such an exercise would certainly be desirable, but would be part of a different study.
} 
where $T_{j}$ is the actual rate of tax of the same type applied by municipality $j$, while $\phi_{i i}$ and $\phi_{i j}$ measure the influence on the tax decisions of municipality $i$ of, respectively, its preferred rate without tax interaction, and the tax decisions of the other municipalities,. The numerical value of $\phi_{i j}$ represents the degree of "neighbourliness" between $i$ and $j$. We suppose that the influence of the one on the other increases in relation to this. Without any tax interaction from the other municipalities on municipality $i$, one has $\phi_{i j}=0$ for all $j$ and $\phi_{i i}=1$, and thus

$$
\widetilde{T}_{i}=T_{i}^{*}
$$

On the other hand, with a maximum interaction, one has $\phi_{i i}=0, \sum_{j \neq i} \phi_{i j}=1$ and thus

$$
\tilde{T}_{i}=\sum_{j \neq i} \phi_{i j} T_{j}
$$

Entity $i$ then only chooses its rate on the basis of the influence that it is subject to from the neighbouring entities.

If all 589 municipalities are considered, and thus equation (3) as a system of 589 equations, the set of coefficients $\phi_{i j}$ is a square 589 × 589 matrix that we will call the "external rate weighting matrix for the choice of preferred rates of municipalities", or more briefly "weighting matrix". Depending on the definition of the term "neighbouring", we will have different matrices of weights made up of the corresponding $\phi_{i j}$.

The formal condition $\sum_{j=1}^{n} \phi_{i j}=1$ expresses the desired rate as a convex combination of the preferred rate without competition and the rates of the neighbouring entities ${ }^{5}$.

\subsection{Dynamic adjustment towards the preferred rate}

We will now denote $T_{i, t}$ as the rate actually applied by municipality $i$ in year $t$, thus the observed rate. It could be considered that this rate is the preferred rate, i.e. that $T_{i, t}=\widetilde{T}_{i, t}$ and this for all $t$. But this hypothesis would be very optimistic regarding the speed and flexibility of tax decision-making in the municipal institution - too optimistic probably. To us, it would seem more realistic to describe the behaviour of decision-makers over time by incorporating the possibility of an adjustment time between the applied rate and the preferred rate.

To this end we will adopt an error correction model (ECM). This type of model has been used with considerable success in the theoretical and empirical literature on dynamic

\footnotetext{
${ }^{5}$ This condition is an identification constraint imposed by the fact that the rates $T_{i}{ }^{*}$ are not observed, and must be estimated or reconstructed from single observations. We note that the model does not change if $T_{i}^{*}$ is multiplied by an arbitrary constant $\mathrm{k}$ and $\phi_{i i}$ is divided by the same constant. This implies that the estimators of the coefficients of $T_{i}^{*}$ are only defined up to a constant of proportionality. An identification constraint thus has to be imposed for each $\phi_{i i}$, or equivalently for each line of the matrix of $\phi_{i j}$ 's. $\phi_{i i}=1$ could for example have been imposed, but it seemed more natural to us to impose that the sum of each line of $\phi_{i j}$ is equal to 1 .
} 
adjustments in the direction of long-term equilibrium solutions, in the presence of adjustment costs ${ }^{6}$.

We use the standard notation $\Delta$ to represent first differences (for example, $\Delta T_{i, t}=T_{i, t}$ $\left.T_{i, t-1}\right)$. In the context of our problem, a formulation of the MEC type is written as follows:

(5) $\Delta T_{i, t}=a+b^{\prime} \Delta Z_{i, t}-v\left(T_{i, t-1}-\widetilde{T}_{i, t-1}\right)$

The central coefficient of the ECM model is $v$, which represents the instantaneous fraction (speed) of adjustment, at a previous disequilibrium, between the actual rate and preferred rate. For any value of $v$, strictly between 0 and 1 , this model converges to a longterm equilibrium in the (hypothetical) scenario of stationarity $\left(\Delta Z_{i, t}=0\right)$, or even of balanced growth $\left(\Delta Z_{i, t}=g_{i}\right.$, where $g_{i}$ designates a growth rate). It is more a theoretical property than an empirical property, as in practice one does not expect to observe a balanced growth of $\Delta Z_{i, t}$.

Of course, as the preferred rates $\widetilde{T}_{i, t}$ are not observed, equation (5) cannot be estimated as such. Equations (2) and (3) have to be substituted for $\widetilde{T}_{i, t}$. This substitution produces the following equation:

(6) $\Delta T_{i, t}=a+b^{\prime} \Delta Z_{i, t}-v\left[\left(1+\phi_{i i}\right) T_{i, t-1}-\phi_{i i} \beta^{\prime} Z_{i, t-1}-\sum_{\substack{j=1 \\ j \neq i}}^{n} \phi_{i j} T_{j, t-1}\right]+\varepsilon_{i, t}$

where $\varepsilon_{\mathrm{i}, t}$ represents the usual error term, assumed to average zero and to be uncorrelated with the regressors (the discrete character of the data implies truncation effects to be discussed in section 4.4 below).

\subsection{The weighting matrix}

It thus remains for us to model the 589 x 589 "weighting" matrix $\phi=\left(\phi_{i j}\right)$. To do this, we adopt a standard logistic formulation in which the logarithms of the $\phi_{i j}$ 's are assumed to be proportional to a linear combination (with weights $\delta$ ) of "socio-economic distance" variables $d_{i j}$ (note that $d_{i i}=0$ for all $i$ ) and are then normalised to unity, i.e:

(7) $\phi_{i j}=\frac{\exp \left(-\delta^{\prime} d_{i j}\right)}{\sum_{k=1}^{n} \exp \left(-\delta^{\prime} d_{i k}\right)}$

The form of the denominator allows for the normalisation constraint $\sum_{j=1}^{n} \phi_{i j}=1$ to be satisfied. After optimisation with respect to $\delta$, it is possible to calculate $\phi_{i j}$ for each pair $i j$, and $\phi_{i i}$ is then calculated using the operation $1-* \sum_{\substack{j=1 \\ j \neq i}}^{n} \phi_{i j}$.

\footnotetext{
6 The interested reader here can consult the fundamental contributions of Sargan (1964), Hendry and Anderson (1977), Davidson, Hendry, Sbra and Yeo (1978), or Nickell (1985).
} 
The choice of the quantities $d_{i j}$ is discussed in section 3.2 below. Two comments apply to the specification of the $\phi_{i j}$ 's:

1. Given the relatively short observation period (14 years), we have limited ourselves to measures of distance which are constant over time (even if this means using sample averages over the observation period), which explains the absence of the index $t$ for $d_{i j}$ and $\phi_{i j}$. There is no conceptual obstacle to using measures of distance that vary in time, but in practice it comes down to calculating a 589 x 589 matrix per year. In our opinion, this is not necessary considering that the subsequent variations selected to calculate $d_{i j}$ would only lead to small changes in $\phi_{i j}$ over time.

2. In the course of the analysis, we examined the question of whether or not the fact of belonging to regions with the same or different languages has an impact on our proximity measurements. There are at least two ways of examining this question. The first consists of adding a dichotomic variable $I_{i j}$ to the list of $d_{i j}$, which takes the value 0 if $i$ and $j$ belong to the same linguistic region, and 1 in the opposite case. A richer model would consist of introducing different values for $\delta$ according to the value of $I_{i j}$, i.e. $\delta_{1}$ for $I_{i j}=1$ and $\delta_{2}$ for $I_{i j}=0$. In practice, this comes down to replacing $\delta$ in equation (7) with:

$\delta_{i j}=\delta_{1} I_{i j}+\delta_{2}\left(1-I_{i j}\right)$

It turned out that the differences between $\delta_{1}$ and $\delta_{2}$ were not significant, and this formulation was thus abandoned in favour of a single $\delta$ common to all pairs of municipalities.

To summarise this section, the model to be estimated is completely characterised by equations (6) and (7).

\section{$3 \quad$ Data and choice of variables}

As already mentioned in Heyndels and Vuchelen (1996), Belgium has a series of characteristics that make it an ideal subject for an empirical study of this type. Firstly, the number of municipalities in Belgium gives us a large sample, as we can work with 589 municipalities each year. Secondly, for all the municipalities only two types of tax, namely the supplements on the personal income tax (hereafter, IPP supplements) and the supplements on the property tax (hereafter, PrI supplements), make up the bulk of municipal tax resources ${ }^{7}$. Thirdly, as these two taxes are additional ("piggyback") to a federal tax and to a regional tax, respectively, the definition of the tax base is entirely uniform because in these two cases it is determined at a higher level. Consequently, we can compare the rates without having to adapt the bases. Finally, the internal borderlines that demarcate the different

\footnotetext{
${ }^{7}$ Tax revenue represents $40 \%$ of the total municipal income, and the two taxes mentioned above constitute more than $80 \%$ of this tax revenue. The rest of the revenue consists of non-tax revenue and grants. For further information, see Flohimont (1999). The acronym IPP stands for Impôt des Personnes Physiques in Belgian tax terminology; similarly, PrI stands for Précompte Immobilier.
} 
responsibilities, including responsibility for tax, of the entities in question are exactly the same. The municipalities are thus institutionally homogeneous. Note that these last three elements facilitate intermunicipal comparisons, both for the taxpayers and for the political decision-makers.

All the data used in the estimate are available for all municipalities for the years 1983 to 1997. The main sources of these data are the National Institute of Statistics, the Ministry of Finance, and the Department of Geography of the Catholic University of Louvain.

We will now describe the data used to estimate equation (6), successively for the IPP supplements and for the PrI supplements.

\subsection{The tax variables}

The IPP supplements are set by each municipality as a percentage of the tax due by the taxpayer to the federal authority ${ }^{8}$. The supplement is expressed in 'centimes' where one centime is one percent of the tax due. The tax base for this federal tax is all the comprehensive income of the taxpayers. The supplements vary from one municipality to the next, between 0 and $10 \%$, with an average of $6.7 \%$ for the whole country.

By contrast, the PrI supplements are expressed by each municipality as a number of hundredths of the PrI rate. If the PrI rate is $1.25 \%$, the supplement, expressed in terms of 'centimes' is here $0.01 \times 0.0125$, a figure that is added to the PrI rate applied to the taxpayer. The tax base for the PrI is the imputed income from the property that the taxpayer owns, an income that is calculated by the (federal) tax department on the basis of objective criteria such as area, year of construction, etc.

The municipal PrI supplements vary from 200 to 4000 from one municipality to the next. The PrI rate itself varies according to the region (because it is a regional tax competence): $1.25 \%$ in Wallonia and Brussels, and 2.5\% in Flanders. 200 centimes thus do not correspond to the same actual tax rate, as it depends on the region where they apply. Consequently, and in order to express the municipal PrI supplements in comparable units across the whole country, it was necessary to convert the figures of these centimes. The rate of municipal property tax, thus re-expressed as a percentage of the tax base (the imputed income), varies between $2.5 \%$ and $50 \%$, with an average of $24.65 \%$.

\subsection{The non-tax explanatory variables}

The introduction of non-tax explanatory variables enables us to distinguish, between the similarities in rates between municipalities, those which are due to socio-economic characteristics from those due to tax interactions.

In order to choose explanatory socio-economic variables, we will use previous studies and make the hypothesis that the set of variables to be used ${ }^{9}$ is not changed by the dynamic aspect introduced here.

In the first set of estimates, we introduced nine explanatory variables, identical for the IPP estimates and the PrI estimates. The estimates then enable us to select the variables which are most relevant for each tax.

\footnotetext{
${ }^{8}$ A consequence of this form of municipal supplement" is that when the tax burden changes at the federal level, the municipal tax revenue changes in the same proportion.

${ }^{9}$ Of course this choice of socio-economic variables is also dictated by the availability of data.
} 
The first socio-economic variable taken into account is the municipal population. In 1997, the number of residents per municipality varied from 85 in Herstappe to 453,030 in Antwerp, with an average of 18,000 in Belgium.

The second variable is the population density. The most densely populated municipality is in the Brussels region, with 191.8 residents per hectare is Saint-Josse and the least densely populated municipality is Léglise, with a density of 0.209 . The Belgian average is 6.7. We interpret this measure as an approximation of the level of urbanisation of the municipality.

The third variable is income per resident in each municipality. In 1983, the poorest municipality, Bertogne, had an annual taxable income per resident of BEF 137,100 (3,999 euros) and the richest was Kraainem with BEF 335,500 (8,317 euros). In 1998, the gap had widened, with the minimum being BEF 192,000 (4,762 euros) per resident in Saint-Josse, and the maximum being BEF 593,200 (14,705 euros) in Lathem-Saint-Martin. The national average was BEF 394,800 (9,787 euros).

Three regional dichotomic variables have also been added to observe whether the rates vary significantly from one region to the next, for reasons other than changes in the socio-economic characteristics included in the model.

For the weights of neighbouring municipalities, four types of "distances" have been introduced: the first is the geographic distance from centre to centre, the second is the income per resident differential between two municipalities $i$ and $j$, the third is the population density differential between $i$ and $j$, and finally the last is the population differential. The choice of these variables for the weights of the municipalities results from the hypothesis that if there is tax mimicry or tax competition, it is because there is, at a given point in time, a comparison of the rates by the political decision-makers or by the taxpayers. This comparison is assumed to be more direct, not only between geographically close municipalities, but also between municipalities with similar characteristics in terms of level of urbanisation, size of population, or income classes.

Table 1 below gives the units in which the explained and explanatory variables are expressed.

Table 1. Variables, symbols and units

\begin{tabular}{|l|l|l|}
\hline Variable & Symbol & Unit \\
\hline Rate of PrI supplement & PrI & 50 centimes \\
Rate of IPP supplement & IPP & $1 / 2 \%$ \\
Distance from centre to centre & DIS & $100 \mathrm{~km}$ \\
Population density & DEN & 100 residents $/ \mathrm{km}^{2}$ \\
Population & POP & 100,000 residents \\
Income per resident & REV & BEF 1,000 \\
Constant & CST & 1 \\
Flanders & FLA & 1 \\
Wallonia & WAL & 1 \\
Brussels & BXL & 1 \\
\hline
\end{tabular}

Note: BEF 1,000 equals 24.79 euros. 


\section{Econometric method}

\subsection{Estimation technique}

The model defined by equations (6) and (7) is non-linear in the parameters $v, \beta$ and $\delta$. The non-linearity in $(v, \beta)$ is eliminated by reparametrising (6) as follows):

(8) $\Delta T_{i, t}=a+b^{\prime} \Delta Z_{i, t}+c^{\prime} \phi_{i i} Z_{i, t-1}-v\left(\left(1+\phi_{i i}\right) T_{i, t-1}-\sum_{j=i}^{n} \phi_{i j} T_{j, t-1}\right)+\varepsilon_{i, t}$

where $c=v \cdot \beta$. We thus have a linear expression in coefficients $(a, b, c, v)$, conditionally to $\delta$ and thus to $\phi_{i j}$. Taking this property of the model into consideration will enable us to considerably simplify the calculation of non-linear ${ }^{10}$ least-squares estimators for all parameters of the model, including $\delta$.

Indeed, for any given value of $\delta$, it is sufficient to calculate the $\phi_{i j}$ 's corresponding to it, to substitute them in equation (8), and to estimate the remaining coefficients by ordinary least squares. We then search for the numerical values of $\delta$ that minimise the sum of the squares of the (estimated) residues of equation (8).

This numerical optimisation programme is written in FORTRAN 77 and uses a very powerful optimisation subroutine based on the simplex method and adapted from Press et al (1966). A complete optimisation calculation takes the order of 25 seconds on a SUNFIRE 3800 workstation.

Before presenting in section 5 the results of the estimate, we have to discuss in the following subsections three essential complementary aspects of the least squares analysis: in subsection 4.2, the statistical calibration of the estimators thus obtained in the form of standard deviations (or of confidence intervals); in subsection 4.3, a selection procedure for the explanatory variables, in order to eliminate the insignificant variables; and in subsection 4.4 , the effects of truncation.

\subsection{Confidence intervals}

The uncertainty inherent in the random nature of the observed sample has to be suitably characterised. This is generally done in the form of standard deviations that measure the statistical dispersion of the estimators. Given the non-linearity of the model, there is no analytical expression for these standard deviations. It is certainly possible to calculate approximations of them, called large sample ones (or asymptotic), but this is at the cost of calculations that can turn out to be awkward.

In this case, we have preferred to use simulation techniques, which with a minimum programming effort enable us to obtain standard deviations corresponding to the actual size of the samples used.

This technique essentially consists of assigning their estimated values to the model parameters and then taking random samples of the error terms $\varepsilon_{i, t}$, and by substitution in equation (6) then deriving fictitious samples of variations of the tax rates (or more

\footnotetext{
${ }^{10}$ Under the hypothesis of normality of the residues $\varepsilon_{\mathrm{i}, \mathrm{t}}$ the method of non-linear least squares coincides with the method of maximum likelihood. As we discuss below, the hypothesis of normality of residues is clearly not satisfied in this application.
} 
specifically, given the dynamic nature of the model, fictitious trajectories of tax rates over the 14 years of our sample). Of course the explanatory variables $Z_{i, t}$, which are not part of the modelling and are exogenous, are kept at their observed value.

The estimation technique described above was applied to each fictitious sample thus obtained (of the size $589 \times 14=8246$ ). For each specification of the model we repeated this simulation procedure 1000 times, and thus obtained 1000 random realisations of the estimation process. Finally, the standard deviations of these 1000 realisations were calculated, thereby obtaining a reliable statistical measure of the statistical dispersion of the estimators (also verifying that the empirical averages of the simulated estimators do not significantly differ from the values selected for the simulation, i.e. the estimators are not significantly biased). The confidence intervals for the estimated coefficients are thus defined as half-length intervals corresponding to two standard deviations, centred on the estimated value of the coefficient.

The validation of this simulation technique of course depends on hypotheses relating to the distribution of the error terms $\varepsilon_{i, t}$, as it is from this distribution that the simulated errors will be drawn. An examination of the estimated residues of the model leads us to reject the standard hypothesis of normality of residues. More specifically, we observe a strong concentration ( 80 to $90 \%$ ) of low residues, accompanied by a small number of often more dispersed residues. Under these conditions, simulations under a hypothesis of normality would lead to excessive concentrations of small simulated unknowns and consequently an excessive "confidence" in the estimated values of the coefficients.

Under these conditions we used a "bootstrap" simulation method, which consists of sampling the unknowns _i,t in their empirical distribution, as obtained using estimators of the coefficients. More precisely, an estimate of the model would produce 8246 estimated residues, which are each allocated a probability of $1 / 8246$ for the simulation procedure (selection with replacement).

\subsection{Selection of the explanatory variables}

We initially have a total of 12 explanatory variables: three for the short term (the $\Delta Z_{i, t}$ 's ), five for the long term (the $Z_{i, t-1}$ 's, complemented by two indicator variables for Flanders and Wallonia - which given the constant term $a$, amount to introducing a specific constant for each of the three regions), and 4 variables for the weights $\phi_{i j}$ (the four types of "distance").

In order to simplify the statistical and economic interpretation of the results, it is generally recommended eliminating variables from the model that do not significantly contribute. In order to do this we start with the most general possible model by including all the available explanatory variables, and then gradually eliminate the least significant ones until a model is obtained where all the coefficients are statistically significant. This elimination procedure is of course done separately for the PrI and IPP, as it can be expected that the variables selected will be different in the two cases. The elimination criterion is the usual criterion of the " $t$ statistic" (ratio between the estimator and its standard deviation) being less than two. This means that all the results presented below are significant in the sense of the $t$ statistic.

Finally, note that to accelerate the interactive selection procedure of variables, it is legitimate to use the least-squares standard deviations rather than those obtained from simulation. The first are lower than the second as, in particular, they do not take account of the uncertainty of the $\delta^{\prime}$ s and thus of the $\phi_{i j}$ 's. It then follows that every variable eliminated on the basis of least-squares standard deviations would also be eliminated on the basis of standard deviations from the simulation. Of course, with regard to the $d_{i j}$, it is appropriate to 
use the simulation standard deviations, which are the only ones available, or, as a first approximation, the $R^{2}$ statistic associated with the least-squares calculation.

\subsection{Effects of truncation}

A detailed examination of the data indicates that municipal tax rates are not continuous variables, but are often rounded to specific fractions of points or to whole numbers of additional centimes. The clearest demonstration of this phenomenon comes from the high percentages of zero changes ( $82 \%$ of observations for the PrI supplements, and $87 \%$ for the IPP supplements). More generally, the large majority of changes to the IPP rates are multiples of $1 / 2 \%$ (between the extremes of $-6 \%$ and $+6 \%$ ). Similarly, the majority of changes to the PrI are in multiples of 50 additional centimes (between the extremes of -1120 and +2120 , both not multiples of 50, and thus exceptional cases). This implicit discretisation raises questions of interpretation and modelling. The most immediate question is whether it is liable to markedly affect the estimates of the model represented by equation (6), in particular in the form of a downward bias in the dynamic adjustment coefficient $v$ (note that $100 \%$ zero adjustments would be perfectly explained by all coefficients in this equation being zero).

The simulation techniques described above answer this question. It is sufficient to do parallel simulations where the simulated tax rates are themselves rounded in order to be representative of the sample observed, i.e. in multiples of $1 / 2 \%$ for the IPP supplements and 50 additional centimes for the PrI supplements.

In particular, we did truncated simulations of the two final versions (PrI and IPP) of our model, as presented below. Without anticipating the detailed analysis of the results, we will see that the dynamic adjustment coefficient $v$ is biased downwards as a result of the truncation (and more particularly, the high number of zero changes), but in a way that does not change the essence of our qualitative conclusions relating to the slowness of the dynamic adjustments towards the long-term equilibrium rates.

\section{The results and their econometric interpretation}

For the PrI supplements and for the IPP suplements, three categories of results have to be considered. The first is made up of estimates of the parameters $\phi_{i j}$, after optimisation of the $\delta$ coefficients. The value of these parameters determines the importance that a municipality attaches to its preferred rate without tax interaction $T_{i, t}^{*}$, as well as to the rates of other municipalities, in the determination of its preferred rate in the presence of tax interactions $\widetilde{T}_{i, t}$, and thus also in the choice of its actual rate of taxation $T_{i, t}$. In addition, these coefficients identify what criteria determine the weight attached by one municipality to the rate of another.

The second category of results relates to the estimate of the fraction $v$ of the difference between the rate actually applied $T_{i, t}$, and the preferred rate with tax interaction $\widetilde{T}_{i, t}$, which is corrected in each period.

Finally, the third category of results relates to the coefficients $b$ and $\beta$ of the non-tax explanatory variables, with $b$ indicating the effect of these variables on the actual annual variations, and $\beta$ measuring their impact on the long term preferred rate $\widetilde{T}_{i, t}$. 


\subsection{Results for the property tax (PrI supplements)}

Table 2 presents the values of the estimated coefficients in the equation for the property tax. It only takes account of the significant variables. The explanatory variables cited in section 3.2 that do not appear in the table do not improve the quality of the estimate. We have thus eliminated them.

Table 2. Estimators for the property tax

\begin{tabular}{|l|l|l|l|}
\hline Coefficient & Variable & Estimator $^{\mathbf{b}}$ & $\boldsymbol{t}_{\text {statistic }^{\mathbf{a}}}$ \\
\hline$a$ & & $0.2345 \mathrm{D}+00$ & 2.962 \\
$b$ & POP $(\underset{d e f}{=} v \beta)$ & $-0.2949 \mathrm{D}+02$ & 2.396 \\
$\beta$ & REV & $0.2467 \mathrm{D}+02$ & 6.310 \\
$v$ & REV & $0.4208 \mathrm{D}+03$ & 6.850 \\
$\delta_{1}$ & & $0.6127 \mathrm{D}+01$ & 16.67 \\
$\delta_{2}$ & DIS & $0.1026 \mathrm{D}+02$ & 7.888 \\
\hline
\end{tabular}

$\mathrm{R}^{2}$ non-linear regression ${ }^{\mathrm{c}}: 0.036$

${ }^{\text {a }}$ The (simulation) $t$ statistic is defined as the absolute value of the quotient between the simulation average and its standard deviation.

${ }^{\mathrm{b}}$ The floating decimal notation of FORTRAN guarantees 4 significant decimals for all estimators.

${ }^{\mathrm{c}}$ This is a gross $\mathrm{R}^{2}$ (not corrected for truncation effects).

Below, we rewrite equation (6) with the estimated coefficients. Because the $\phi_{i i}$ 's and $\sum_{\substack{j=1 \\ j \neq i}}^{n} \phi_{i j}$ 's are specific to each municipality, we cannot give them a value in this general equation. That is why, for indicative purposes, we write it with the estimated coefficients for a given municipality, Ixelles, that we denote as $x l$ :

(9)

$\Delta \operatorname{Pr} I_{x l, t}=0,2345-29,49 . \Delta P O P_{x l, t}-0,06127\left[\left(1+\phi_{x l, x l}\right) \operatorname{Pr} I_{x l, t-1}-\phi_{x l, x l}\left(402,8 R E V_{x l, t-1}\right)-\sum_{j=1}^{n} \phi_{x l j} \operatorname{Pr} I_{j, t-1}\right]+\varepsilon_{x l, t}$

where

$$
\begin{aligned}
(10) \phi_{x l j} & =\frac{\exp \left(-10,26 D I S_{x l j}-5,361 D D E N_{x l j}\right)}{\sum_{k=1}^{n} \exp \left(-10,26 D I S_{x l k}-5,361 D D E N_{x l k}\right)} \\
\phi_{x l x l} & =1-\sum_{\substack{j=1 \\
j \neq x l}}^{n} \phi_{x l j}=0,254
\end{aligned}
$$


Before going into a systematic examination of the coefficients, an important comment concerning the $R^{2}$ of this estimate is in order. It shows that the predictive quality of the model is particularly low, of the order of 3.6\%. This is due to several factors. First of all, panel data usually generate a low $R^{2}$. Secondly, the data are discrete while the model has been specified for continuous variables. Thirdly, first differences are used. Finally the list of variables $Z_{i}$ taken into consideration is clearly not exhaustive - it thus has to be completed.

\section{a) The value of the $\phi_{i j}$ 's}

For the property tax, the optimisation of the value of the $\phi_{i j}$ 's through the coefficients $\delta$, shows us that the geographic distance (DIS) and the population density differential (DDEN) have a significant impact on the weight attached to the rate of another municipality when choosing its own rate. This means that when deciding its supplement to the property tax rate, a municipality $i$ takes account of the tax rate supplements of the municipalities that $\left(1^{\circ}\right)$ are not too far away in physical distance and $\left(2^{\circ}\right)$ are relatively comparable in terms of population density. In other words, the importance that municipality $i$ attaches to the rates applied in $j$ is inversely proportional to these two types of distance.

The significant nature of these two coefficients shows the importance of going a step further than the studies mentioned in the review of the literature, and of not being limited to the single criterion of geographic distance. Geographic distance plays a certain role, but it is not the only one.

Thanks to these coefficients, it is possible to calculate the $\phi_{i i}$ of each municipality, as well as the $\phi_{i j}$ of each pair of municipalities. The $\phi_{i i}$ 's vary from 0.06 to 0.70 depending on the municipality (with an average of 0.122 ). In the long term, 6 to $70 \%$ of the actual rate of property tax of a municipality depends on its preferred rate without tax competition, and 30 to $94 \%$ on the rate of the closest municipalities in distance and in population density.

For municipality $x l$ in particular (see equation (10)), we interpret the results in the following way: $25.4 \%$ of the preferred long term rate in the presence of tax interaction $\widetilde{T}_{x l, t}$ depends on its preferred rate in the absence of tax interaction $\widetilde{T}_{x l, t}^{*}$ (and thus on its specific socio-economic characteristics), and $74.6 \%$ on the rate of neighbouring municipalities.

An examination of the individual $\phi_{i i}$ 's shows that the $\phi_{i i}$ 's of the municipalities of the Brussels region are relatively large on average (the Brussels average is 0.282): compared with the Flemish and Walloon municipalities, the municipalities of the capital are less influenced by their neighbours and they attach relatively more importance to their preferred rate without tax interaction. The reason for this specific Brussels characteristic could come from important externalities between these municipalities and the peripheral municipalities in terms of public goods and services. In fact a quarter of the daytime users of Brussels infrastructure are commuters from the suburbs ${ }^{11}$. Another specific aspect of the Brussels region that could explain this difference in behaviour is the very dense structure as well as the value of its real estate.

The specific character of the Brussels $\phi_{i i}$ 's reinforces our idea that an increase in the number of explanatory variables, and in particular those concerning the supply of public goods and services as well as the value of the real estate, would markedly improve the predictive value of our model.

The estimated coefficients of equation (10) show the following:

\footnotetext{
${ }^{11}$ See LAMBERT, TULKENS et al. (1999)
} 
1. With equal population density differentials $(=\mathrm{DDEN})$ and with distances of, say, 20 $\mathrm{km}$ between $i$ and $j$, and $50 \mathrm{~km}$ between $i$ and $h$, the weight attached by $i$ to $j$ is 21.7 times larger than the weight attached by $i$ to $h$.

2. With equal distances, and with a population density differential between $i$ and $j$ equal to 10 residents $/ \mathrm{km}^{2}$ and a similar differential between $i$ and $h$ equal to 200 residents $/ \mathrm{km}^{2}$, the weight attached by $i$ to $j$ is 124 times greater than the weight attached by $i$ to $h$.

Remember that the sum of the $\phi_{i j}$ 's is equal to 1 and that there are $589 \phi_{i j}$ 's. Each one is thus very small, and the weight attached to the municipalities further away, in distance or in terms of population density differential, rapidly tends towards 0 .

\section{b) The value of the adjustment coefficient $v$}

The estimated adjustment coefficient is 0.0612 and is highly significant. This value means that when in municipality $i$ a difference is observed at time $t$ between its actual rate $T_{i, t-}$ 1 and its preferred rate $\widetilde{T}_{i, t-1}$, this municipality adjusts its actual rate at time $\boldsymbol{t}$ by $2.12 \%$ of the observed difference. The dynamic adjustment is thus very slow.

One should also keep in mind that the preferred rate of the municipality $\widetilde{T}_{i, t}$ constantly varies in relation to changes in the socio-economic characteristics of municipality $i$ and the rates of neighbouring municipalities.

It is also important to note that the specification of the model implies that this adjustment coefficient is an average of the adjustments over time. In reality, it is generally observed that municipalities keep their rate constant for a few years, and then make a change larger than $6.12 \%$. Such behaviour could be attributed to the fixed costs (administrative and political) involved in a change of tax.

On the basis of these explanations, we can deepen the interpretation of equation (9) specific to municipality $x l$ in the following way. Let us make the hypothesis that all socioeconomic characteristics of municipality $x l$ are constant over time (the preferred rate in the absence of tax interactions is consequently fixed) and that the number of centimes in the PrI supplements of all other municipalities is increased by 100 at time $t-1$. Then, the preferred long term equilibrium supplement of $x l$ increases by 74.6 centimes, as the equation implies that $74.6 \%$ of it depends on what happens in neighbouring municipalities. As to the actual supplements, on average, municipality $x l$ will make at time $t$ an adjustment of $6.12 \%$ towards this new equilibrium preferred rate, i.e. it will increase its PrI supplement by 4.55 centimes (= $6.12 \% \times 74.6)$.

\section{c) The value of the coefficients of the explanatory variables.}

The socio-economic variables with significant coefficients in the equation for the PrI supplements are the income per resident (REV) and the number of residents (POP). However, these two variables act in different ways: the population variations influence the short-term decisions through the vector of coefficients $b$, while the income per resident determines, through the vector of coefficients $\beta$, the level of the long term preferred rate $\widetilde{T}_{i, t}$ and the (very) gradual adjustment towards it.

We will not dwell on the interpretation of the short term coefficient $b$, as it is not a key parameter in our model. Moreover, as we have said, the predictive value of the model is low and makes the interpretation of short term movements awkward. 
Instead, let us look at the coefficient $\beta$ determining the long term objective. If, for a municipality, the annual income per resident reaches, from time $t$ on, a permanent level of 5,000 francs higher than before, its preferred rate $\widetilde{T}_{i, t}$ is changed and increases by $\phi_{i i} \mathrm{x} 5 \mathrm{x}$ 0.4026 , all other things remaining equal. In the specific case of municipality $x l$ this rate $\widetilde{T}_{x, t}$ increases by $0.254 \times 5 \times 0.4026=0.51$. In terms of additional centimes, this means that the preferred long term rate increases by 25.5 (as the $T$ 's are expressed in units of 50 centimes for the PrI supplements). Given the estimated adjustment coefficient, the model predicts that the municipality will adapt its actual rate towards this new preferred rate, by $25.5 \times 0.06=1.53$ centimes per year. The sign of this estimated coefficient can be seen as a confirmation of the idea that the demand for public goods and services increases with income, and that the greater supply of these goods and services requires additional financial resources, which the municipality can obtain through a higher tax burden.

\subsection{Results for personal income tax (IPP supplements)}

Table 3 shows values of the coefficients estimated in the equation for the IPP suppements. Just like for the PrI supplements. Only significant variables are retained. The same comment as in the previous section thus applies to $\mathrm{R}^{2}$, which, although it has now a double value, is nevertheless very low.

Table 3. Estimators for personal income tax

\begin{tabular}{|c|c|c|c|}
\hline Coefficient & Variable & Estimator $^{b}$ & $t$ statistic $^{\mathrm{a}}$ \\
\hline$a$ & & $0.7836 \mathrm{D}-01$ & 3.891 \\
\hline$b_{1}$ & $\mathrm{DEN}$ & $-0.8068 \mathrm{D}+01$ & 2.691 \\
\hline$b_{2}$ & REV & 0.4391D-02 & 4.390 \\
\hline$c_{1}\left(\underset{d e f}{=v} v \beta_{1}\right)$ & DEN & $0.9495 \mathrm{D}+00$ & 7.020 \\
\hline$c_{2}\left(\underset{d e f}{=} v \beta_{2}\right)$ & POP & $0.1 .12 \mathrm{D}+01$ & 4.285 \\
\hline$c_{3}\left(\underset{d e f}{=} v \beta_{3}\right)$ & WAL & $0.1217 \mathrm{D}+01$ & 11.50 \\
\hline$\beta_{1}$ & $\mathrm{DEN}$ & $0.9000 \mathrm{D}+01$ & 7.072 \\
\hline$\beta_{2}$ & POP & $0.9595 \mathrm{D}+01$ & 3.923 \\
\hline$\beta_{3}$ & WAL & $0.1153 \mathrm{D}+02$ & 12.17 \\
\hline$v$ & & $0.1055 \mathrm{D}+00$ & 23.44 \\
\hline$\delta_{1}$ & DIS & $0.6630 \mathrm{D}+01$ & 7.688 \\
\hline$\delta_{2}$ & DREV & $0.5268 \mathrm{D}-01$ & 5.247 \\
\hline
\end{tabular}


The estimated coefficients for the IPP yield the following equation:

$$
\begin{aligned}
(11) \Delta I P P_{i, t} & =0,07836-8,068 \Delta D E N_{i, t} \\
& +0,004391 \Delta R E V_{i, t}-0,1055\left(I P P_{i, t-1}\right. \\
& -\phi_{i i}\left(9,000 D E N_{i, t-1}\right. \\
& \left.+9,592 P O P_{i, t-1}+11,53 W A L_{i}\right) \\
& \left.-\sum_{j=1}^{n} \phi_{i j} I P P_{j, t-1}\right)+\varepsilon_{i, t}
\end{aligned}
$$

where

(12) $\phi_{i j}=\frac{\exp \left(-6,630 D I S_{i j}-52,68 D R E V_{i j}\right)}{\sum_{k=1}^{n} \exp \left(-6,630 D I S_{i k}-52,68 D R E V_{i k}\right)}$

\section{a) The value of the $\phi_{i j}$ 's}

For the IPP supplements, the estimate of $\delta$ shows that it is the rates of the geographically close municipalities and those similar in terms of income per resident that influence most the municipal choices. As with the property tax, we see that it was useful to analyse in more detail the criteria to be considered in the definition of "neighbourliness": indeed, while we observe that the geographic distance plays the same role as shown by previous studies, we see here too that it is not the only one. But our analysis shows that the additional criterion to be considered differs according to the tax studied: income per resident for the IPP supplements and population density for the PrI supplements.

For the IPP, the $\phi_{i i}$ 's vary from 0.063 to 0.843 , with an average of 0.140 . In this case, just as with the PrI, the average over the municipalities of the Brussels region average is higher $(0.173)$ than in the other regions but less markedly so.

The estimated coefficients of equation (12) show the following:

1. With equal income differentials (=DREV), and with distances of $20 \mathrm{~km}$ between $i$ and $j$ and $50 \mathrm{~km}$ between $i$ and $h$, the weight attached by $i$ to $j$ is 7.3 times larger than the weight attached by $i$ to $h$.

2. At equal distances, with an income differential between $i$ and $j$ equal to 20,000 $\mathrm{BEF} /$ resident, and the differential between $i$ and $h$ equal to $100,000 \mathrm{BEF} /$ resident, the weight attached by $i$ to $j$ is 67 times greater than the weight attached by $i$ to $h$.

\section{b) The value of the adjustment coefficient $v$}

With the IPP supplements, the adjustment coefficient is 0.1055 . When there is a difference between its actual rate and its long term equilibrium rate, municipality $i$ adjusts its actual rate, annually and on average, by $10 \%$ of this difference. Just as with the adjustment 
coefficient for the PrI supplements, the coefficient for the IPP supplements is highly significant.

It is interesting to note that the speed of adjustment is greater with IPP than with $\operatorname{PrI}$ supplements. Two interpretations are possible. On the one hand, it can be attributed to the fact that the tax base for the IPP, which is the income of the taxpayer ${ }^{12}$, is more mobile than with the PrI, the registered income of the building ${ }^{13}$. On the other hand, we can see there an indication of the fact that tax interaction in IPP supplements and tax interaction in PrI supplements do not occur through the same transmission channels, and thus do not give rise to the same rates of adjustment.

\section{c) The value of the coefficients of the explanatory variables}

A distinction again has to be made between the socio-economic characteristics that influence the short term tax rate and those that influence the long term preferred rate. Among the variables with a short term effect, are the population density and the income per resident. Among the variables with an effect on the long term equilibrium rate, are the population density and the number of residents, and being in Wallonia.

For the same reasons as those given for the PrI supplements, we will not look at the short term aspect. However, we do have to make one comment concerning the explanatory variable "population density", which has both a short term and long term effect with coefficients of opposite signs. When the density increases, the model predicts that the IPP rate adjusts downwards in the short term. In the long term however, the pressure on the equilibrium rate is upwards. The population density thus plays an ambiguous role on public needs and goods: a higher density can have a downward impact on taxation because of economies of scale in the supply of services, but a high density can also lead to needs linked to congestion, security, etc.

Among the socio-economic variables with an impact on the preferred long term rate, three are significant: the population density, the number of residents and the regional dichotomic variable for Wallonia. When the first two incur a permanent level change, the preferred long term rate is changed.

Thus, with all other things remaining equal, when $D E N_{i}$ increases by 100 resident $/ \mathrm{km}^{2}$, $\widetilde{T}_{i, t}$ increases by $\phi_{i i} \times 1 \times 9$. In the case of municipality $x l$, which has a $\phi_{x l, x l}$ of $0.38, \widetilde{T}_{i, t}$ increases by 3.5. This means that if its preferred rate was $6 \%$, the new preferred rate after an increase in the population density goes to $6+1.7=7.7 \%$ (note: the units for the IPP supplements are $1 / 2 \%$, which is why $\widetilde{T}_{i}$ has to be divided by 2 for the interpretation). Note, it is the new preferred long term rate; in fact, the municipality will only adjust annually at a rate of $10 \%$, as the estimated $v$ is 0.1055 .

On the other hand, with all other things equal, if $P O P_{i}$ increases by 1000 residents, then $\widetilde{T}_{i, t}$ increases by $\phi_{i, i} \times 0.01 \times 9.59$. If municipality $i$ has an average $\phi_{i, i}$, i.e. 0.38 , the $\widetilde{T}_{i, t}$ increases by 0.038 . This means that if the preferred rate was $6 \%$, the new preferred rate after the population increase goes to $6.019 \%$ (same comment as above). Again, the municipality will only adjust to this new long term rate at a pace of $10 \%$ per year.

For the interpretation of the regional dichotomic variable coefficient, remember that it is the difference between a Walloon municipality and a municipality of another region. We

\footnotetext{
12 The IPP is located in the municipality where the taxpayer lives.

${ }^{13}$ The PrI is located in the municipality where the building is located.
} 
can then say that on average, if municipality $i$ is Walloon, and has an average $\phi_{i, i}$, i.e. 0.14 , then its preferred long term rate is $(0.14 \times 1 \times 11.53) / 2=0.807$ higher than the rate of a nonWalloon municipality that has the same $\phi_{i, i}$. The introduction of regional dichotomic variables thus shows that the fact of belonging to the Walloon region systematically implies higher rates than the other regions, with all other things being equal. It could be that DEN and POP are lower on average for the Walloon municipalities than for the Flemish and Brussels municipalities. In this case, the effect of WAL could only serve to counterbalance these differences. This result could also indicate that other characteristics specific to the Walloon region have not been taken into account in our explanatory variables, such as specific needs of these municipalities relating to social protection, for example.

\section{Summary and conclusions}

The objective of this article was to econometrically test the existence of tax interactions between Belgian municipalities. Two types of tax that the municipalities have control over have been considered: supplements to personal income tax (IPP) and supplements to the property tax (PrI). A dynamic model has been specified and estimated from panel data of 589 Belgian municipalities over a 15 year period.

The results obtained essentially relate to two points. On the one hand, they show evidence of interaction between municipalities in the choices of the rates of the two taxes during the period studied. This interaction is all the more important when the municipalities are close and similar (a new finding from this study). With regard to IPP supplements, it is the similarity in terms of income per resident that matters, whereas for the PrI supplements it is the similarity in terms of population density that counts.

On the other hand, thanks to the dynamic specification introduced here, it has been possible to see that adjustments in response to the rates of other municipalities only occur slowly. For the property tax supplements, the difference between the applied rate and the desired rate due to interactions is reduced by only $6 \%$ per year. Thus 15 years is required before the preferred rate is reached, which in the meantime is liable to have changed. For the IPP supplements, this gap is reduced at $10 \%$ per year.

It can be concluded that while tax interaction between municipalities - the only one observable in Belgium - is not absent in this country with IPP and PrI supplements, its importance is low, arguably too low to constitute a clear and major obstacle to the implementation of tax decentralisation policies in general.

In this perspective, it should be pointed out that the model is open to other uses, in particular for the purpose of simulating coordinated municipal tax policies. It could be a major extension of the work presented here, that our methodological results be used to prepare cooperation decisions aimed at tax harmonisation between the institutions involved, a perspective that seems to be sorely missing from the current debates.

Finally, the specification of the model could be improved, mainly by better modelling the "discrete" (time) nature of the tax decision process, and also by using a simultaneous estimate of the equations that model the two taxes. These extensions would increase the explanatory value of the model. 
ASHWORTH, J. and HEYNDELS, B. (1997), 'Politicians preferences on local tax rates : an empirical analysis", European Journal of Political Economy.

BESLEY, T. and CASE, A. (1990), "Incumbent behavior : vote seeking, Tax setting and Yardstick competition", American Economic Review, 85, 1, pp. 25-45.

BESLEY, T. and ROSEN, H. (1998), “'Vertical externalities in tax setting : Evidence from gasoline and cigarettes", Journal of Public Economics, Vol. 70, 3, pp. 383-398.

BOADWAY, R. and HAYASHI, M. (2000), “An empirical analysis of intergovernmental tax interaction : The case of business income taxes in Canada", mimeo, Queen's University, Ontario, Canada.

BRUECKNER, J.K. (1996), “'Testing for strategic interaction among local governments : the case of growth controls", Journal of Urban Economics, forthcoming.

BRUECKNER, J.K. and SAAVEDRA, L.A. (1998), 'Do local governments engage in Strategic Tax Competition ?", Department of Economics, University of Illinois at UrbanaChampaign, Mimeo.

CASE, A. (1993), 'Interstate tax competition after TRA86", Journal of policy analysis and management, 12, 1, pp. 136-148.

CASE, A., ROSEN, H.S. and HINES, J.R. (1993), "'Budget spillovers and fiscal policy interdependence : evidence from the states", Journal of Public Economics, 52, pp. 285-307.

DAVIDSON, J.E.H., HENDRY, D.F., SBRA, F. and YEO, S(1978), “Econometric modelling of the aggregate time-series relationship between consumer's expenditure and income in the United Kingdom", Economic Journal, 88, 661-692.

FELD, L. and KIRSCHGÄSSNER, G. (2000), “'Income tax competition at the state and local level in Switzerland", CESifo Working Paper Series, 238, Munich.

FLOHIMONT, O. (1999) "Les finances des pouvoirs locaux sous l'angle régional", Bulletin du Crédit Communal, n² 210, 1999/4, Bruxelles.

GENSER, B. and WECK-HANNEMANN, H. (1993), 'Fuel taxation in EC countries: A politico-economy approach", University of Konstanz, mimeo.

GOODSPEED, T. J. (1998), "Tax competition, benefit taxes and fiscal federalism", National Tax Journal, Vol. LI, 3, pp. 579-586.

GOODSPEED, J. T. (October 1998), "'Tax structure in a federation", Hunter College mimeo.

GOODSPEED, J. T. (March 1999), “Tax competition and tax structure in open federal economies : evidence from OECD countries with implications for European Union", Hunter College, mimeo. 
HENDRY, D.F. and ANDERSON, G.J. (1977), ' Testing dynamic specification in small simultaneous systems : An application to a model of building society behaviour in the United Kingdom", in Intriligator, M.D. (ed.) Frontiers in quantitative economics, Vol. 3, pp. 361-383. Amsterdam: North Holland Publishing Company.

HENDRY, D.F. and VON UNGERN-STERNBERG, T. (1981), "'Liquidity and Inflation Effects on Consumers Expenditures", in: A.S. Deaton (Ed.) Essays in the Theory and Measurement of Consumers' Behaviour, Cambridge: Cambridge University Press, Chapter 9.

HEYNDELS, B. (1990), “De financiering van de gewesten via een aanvullende personenbelasting en de betekenis hiervan voor de Belgische gemeenten", Cahiers Économiques de Bruxelles, 127, 3ème trimestre.

HEYNDELS, B. and SMOLDERS, C. (1994), "Fiscal illusion at the local level : Empirical results for the Flemish municipalities", Public Choice, 80, pp. 325 -- 338.

HEYNDELS, B. en VUCHELEN, J. (1989,)" Gemeentenbelastingen en belastbaar inkomen", Tijdschrift voor Economie en Management, Vol. XXXIV, 1, pp. 57-76.

HEYNDELS, B. en VUCHELEN, J. (1998), “Tax mimicking among Belgian municipalities", National Tax Journal, Vol. LI, 1, pp. 89-101.

HINES, J.R. (1993), ' 'Budget spillovers and fiscal policy interdependance. Evidence from the states", Journal of Public Economics, 52, pp. 285-307.

HINES, J. (1999), "Lessons from behavioral responses to international taxation", National Tax Journal, Vol. 52, 2, pp. 305-322.

HUGOUNENQ, R., LE CACHEUX, J. et MADIES, Th. (1999), 'Les risques de la concurrence fiscale en Europe", Problèmes économiques, 15 décembre 1999.

LADD, H. F. (1992), "Mimicking of local tax burdens among neighboring countries", Public Finance Quaterly, 20, 4, pp. 450-467.

LAMBERT, J.-P., TULKENS, H. et al. (1999) Les modes alternatifs de financement de Bruxelles, Rapport de recherche réalisée à la demande de Monsieur GRIJP, Ministre de la recherche scientifique de la Région de Bruxelles-Capitales, Facultés Universitaires SaintLouis, Bruxelles.

MADDALA, G.S. (1993), " The econometrics of panel data", in : The international library of critical writings in econometrics 1, Vol. I and II, Edward Elgar.

NICKELL, S.J.(1985), “Error correction, partial adjustment and all that : an expository note", Oxford bulletin of economics and statistics, n47, 119-130.

PHILLIPS, A.W. (1954), "'Stabilization Policy in a Closed Economy", Economic Journal, pp. 290-323. 
PHILLIPS, A.W. (1957), "Stabilization Policy and the Time Form of Lagged Responses", Economic Journal, nº7, pp. 265-277.

PRESS, W.H., FLANNERY, B.P., TEUKOLSKY, S.A. and W.T. VETTERLING (1986), Numerical Recipes. The art of Scientific Computing, Cambridge University Press. Cambridge

SARGAN, J. D(1964), "Wages and prices in the United Kingdom : A study in econometric methodology (with discussion)", in Hart, P.E., Mills, G. and Whitaker, J.K. eds.), Econometric analysis for national economic planning, Vol. 16 of COLSTON PAPERS, pp.25-63. London: Butterworth Co.

VAN DER STICHELE, G. et VERDONCK, M. (2001), “'Les modifications de la loi $\mathrm{sp}^{\prime}$ \{eciale de financement dans l'accord du Lambermont", Courrier hebdomadaire, $\mathrm{n}^{\circ} 1733$, CRISP, Bruxelles.

WILSON, J. D. (1999), "Theories of tax competition", National Tax Journal, Vol. LII, 2, pp. 269-304. 